\title{
Double Weighted Moving Average: Alternative Technique for Chemicals Supplier's Sales Forecast
}

\author{
Ma. Del Rocio Castillo E. ${ }^{1}$, Ma. Magdalena Chain Palavicini ${ }^{1}$, Roberto Del Rio Soto ${ }^{1} \&$ M. Javier Cruz Gomez ${ }^{2}$ \\ ${ }^{1}$ Faculty of Accounting and Administration, Universidad Nacional Autónoma de México (UNAM), Coyoacán, \\ México \\ ${ }^{2}$ Faculty of Chemistry, Universidad Nacional Autónoma de México (UNAM), Coyoacán, México \\ Correspondence: M. Javier Cruz Gomez, Faculty of Chemistry, Universidad Nacional Autónoma de México (UNAM), \\ Coyoacán, 04510, México.
}

Received: May 19, 2016

doi:10.5430/ijba.v7n4p58
Accepted: June 8, 2016

Online Published: July 6, 2016

URL: http://dx.doi.org/10.5430/ijba.v7n4p58

\begin{abstract}
The proposed technique which has been called Double Weighted Moving Average (DWMA) was compared in performance with five already analyzed, Castillo, M. del R. et al. (2015), quantitative techniques: simple moving average, weighted moving average, exponential smoothing, trend projection and lineal regression; in order to improve the accuracy of chemicals supplier's sales forecasts used to plan operations in Mexican industry. These forecasts are complex because; some Mexican companies handle up to 500 different materials and have up to 1000 customers with changing consumption patterns.

The present DWMA forecasting technique was added to the system (algorithms and software) developed in the first part of the work, Castillo, M. del R. et al. (2016). Errors obtained with the five originally proposed techniques were compared versus the error obtained with the new technique.

The system was applied to two Mexican chemicals suppliers. The new DWMA proposed technique showed, for the company one, better performance than the other five techniques, because most of its products have sales behavior with various patterns combined with seasonality. In the case of the company two, DWMA technique turned out to be the third of the six techniques used with lower error, because the behavior of most of its products presents random behavior sales data. The symmetric medium absolute percentage error, SMAPE, measurement is used on the system to measure each technique error. On the other hand, DWMA technique was better than the forecasting technique used in each company, in $56 \%$ for the first company products, who uses simple moving average, and in $81.8 \%$ of the second company products, who uses trend projection.
\end{abstract}

Keywords: sales forecasting techniques, double weighted moving average (DWMA), symmetrical medium absolute percentage error (SMAPE)

\section{Introduction and Background}

The forecasting plays a central role in the function of a company's operations, Hahmias, S. (2007). Any business planning is based on forecasts. The two company functional areas that make greater use of the forecasts are marketing and production. Marketing usually forecasts sales of new and existing lines product. The production department uses sales forecasts for planning operations.

Effective planning, Heizer, J. (2009), in short and long-term prognosis depends on the demand for the company's products. Good forecasts are crucial to all aspects of the business: The prognosis is the only estimate of the demand until the actual demand is known. Therefore, forecasts of demand guide decisions in the areas of human resources, capacity and supply chain management.

Sales forecast model makers developed the initial models in the 1950s and 1960s, have been accumulating experience in sharpening their models, Crawford, M. (2011), and are now a mature, large and profitable industry. Their models are readily available to consumer packaged goods innovators and quite inexpensive compared to test markets and rollouts. The models allow diagnostic output as well as sensitivity testing. Unfortunately, the models: require massive amounts of data to work well, are built on assumptions no longer valid (For example, reliance on mass advertising and easy-to-get distribution) and become so complex that managers are wary of them.

It is interesting to note that, the most successful firms by far use the simplest methodology and require the least data. 
For Chase, R. (2014), forecasts are vital for any business organization, as well as any major management decision. Forecasts are the bases of the long-term corporate planning. In the functional areas of finance and accounting, forecasts represent the basis for budgeting and controlling costs. Marketing depends on sales forecast to plan new products, estimate compensations to the sales staff and make other key decisions. With forecasts, production and/or operations staff makes regular decisions like the process selection, capacity and production planning, distribution scheduling, and proper raw materials and final product inventories.

Forecasting is fundamental in any planning effort. In the short term, and in order to respond to changes in demand, forecast allows adjusting the needs of: materials, spare parts, services, schedules and varying labor. In the long term, it is required as a basis for predicting strategic changes, such as the development of new markets, create new products or services and expand or build up new facilities.

Otherwise, the sales and operations planning is a process that helps to provide better customer service, to low inventory handling, to offer customers shorter delivery times, to stabilize production rates and to make easier the business handling for the management staff.

Moreover, in order to have sales forecasts more accurate, or with a minor mistake, it is proposed a new quantitative technique for sales forecasting, called Double Weighted Moving Average (DWMA). A system (algorithm and software) was developed for calculating the forecasted sales for each product by applying five established and the new proposed techniques. The system evaluates the error of each technique and selects the lowest error one.

\section{Forecasting Techniques}

Forecasting is the art and science of predicting future events, Heizer, J. (2009). It may involve the management of historical data to project future through some kind of mathematical model. It can be a subjective or intuitive prediction of future, or a combination of both, i.e., a mathematical model adjusted for the judgment of an administrator.

Demand forecasts are projections of demand for products or services of a company. These forecasts, also called sales forecasts, orienting production, capacity and scheduling company systems, and serve as inputs in financial planning, marketing and personnel.

To Nahmias, S. (2007), the characteristics of the forecasts are:

- Usually they will be wrong.

- A good forecast also gives a measure of error.

- Forecasting several units together is easier than with individual units.

- The more a long future forecast is made; the less accurate it will be.

- A forecasting technique should not be used to exclude known information.

The forecasting model, Chase, R. (2014), which a company should choose depends on:

1. The time horizon they will be forecasted.

2. The data availability.

3 . The required accuracy.

4. The size of the budget for forecasting.

5. The availability of qualified personnel.

Guide to select an appropriate method of forecasting:

\begin{tabular}{|c|c|c|c|}
\hline Forecasting Method & $\begin{array}{l}\text { Number of historical } \\
\text { data }\end{array}$ & Pattern data & Forecast horizon \\
\hline Linear regression & $\begin{array}{l}10-20 \text { observations for } \\
\text { temporality. }\end{array}$ & $\begin{array}{l}\text { Stationary season, trends } \\
\text { and seasonality }\end{array}$ & Short to medium \\
\hline $\begin{array}{l}\text { Simple } \\
\text { Average }\end{array}$ & $\begin{array}{l}\text { 6-12 months, often } \\
\text { weekly data }\end{array}$ & $\begin{array}{l}\text { Data must be stationary } \\
\text { (i.e., They will be } \\
\text { without trend and } \\
\text { seasonality) }\end{array}$ & Short \\
\hline $\begin{array}{l}\text { Weighted moving } \\
\text { average and simple } \\
\text { exponential smoothing }\end{array}$ & $\begin{array}{lll}\text { For starting } & \text { will be } \\
\text { needed 5 } 5 & \text { to } & 10 \\
\text { observations } & & \end{array}$ & $\begin{array}{l}\text { The data must be } \\
\text { stationary }\end{array}$ & Short \\
\hline
\end{tabular}


A company, Chopra, S. (2010), may find it difficult to decide which method is most appropriate for forecasting. In fact, several studies have indicated that using multiple forecasting methods to create a combined forecast is more effective than using any one method alone.

Basic approach to demand forecasting.

The following basic, six-step approach helps an organization perform effective forecasting.

1. Understand the objective of forecasting.

Every forecast supports decisions, so an important first step is to identify these decisions clearly.

2. Integrate demand planning and forecasting throughout the supply chain.

A company should link its forecast to all planning activities throughout the supply chain. These include capacity planning, production planning, promotion planning, and purchasing, among others. This link should exist at both the information system and the human resources management level. As a variety of functions is affected by the outcomes of the planning process, it is important that all of them be integrated into the forecasting process.

3. Understand and identify customer segments.

A firm must identify the customer segments, the supply chain serves. Customers may be grouped by similarities in service requirements, demand volumes, order frequency, demand volatility, seasonality, and so forth. In general, companies may use different forecasting methods for different segments. A clear understanding of the customer segments facilitates an accurate and simplified approach to forecasting.

4. Identify the major factors that influence the demand forecast.

Next, a firm must identify demand, supply and product-related phenomena that influence the demand forecast. On the demand side, a company must ascertain whether demand is growing, declining, or has a seasonal pattern.

5. Determine the appropriate forecasting technique.

In selecting an appropriate forecasting technique, a company should first understand the dimensions that are relevant to the forecast. These dimensions include geographic area, product groups, and customer groups. The company should understand the differences in demand along each dimension and will likely want different forecast and techniques for each dimension.

6. Establish performance and errors measures for the forecast.

Companies should establish clear performance measures to evaluate the accuracy and timeliness of the forecast. These measures should be highly correlated with the objectives of the business decisions based on these forecast.

\section{Method}

\subsection{Hypothesis}

Considering hypothesis test used:

$\mu=$ Average error of prediction techniques Sales (1-Simple Moving Average, 2-Weighted Moving Average, 3-proyeccción trend, 4-Exponential Smoothing, 5-Linear Regression and 6-Double Weighted Moving Average.

$$
\begin{gathered}
\mathrm{H}: \mu_{6} \geq \mu_{1}, \mu_{2}, \mu_{3}, \mu_{4}, \mu_{5} \\
\mathrm{H}: \mu_{6}<\mu_{1}, \mu_{2}, \mu_{3}, \mu_{4}, \mu_{5} \\
\mathrm{H}_{0}: \mu_{6} \geq \mu_{1}, \mu_{3} \\
\underset{\mathrm{a}}{\mathrm{H}: \mu_{6}}<\mu_{1}, \mu_{3}
\end{gathered}
$$

\subsection{Universe}

According to the Pochteca census from the National Association of the Chemical Industry, there are 300 chemicals distributors in México.

\subsection{Procedure}

Heizer, J. (2009) proposed seven steps in order to initiate the design and implementation of a forecasting system. All of them were followed for the present development. They are:

I. Determine the forecast use: The chemicals suppliers use forecasts to meet its future sales, in order to better plan their operations. 
II. Select the aspects to predict: Chemicals future sales of a company are forecasted based on its historical sales data.

III. Determine the time horizon of the forecast: The forecast is usually made for the short and medium term (extension of time up to one year). It is also used to plan purchasing, scheduling work, determining levels of labor, assigning work and decide production levels.

IV. Select forecasting models: It was used simple moving average, weighted moving average, the trend projection, exponential smoothing and simple linear regression. These five techniques plus the Double Weighted Moving Average (DWMA) technique are used to predict the short and medium term. DWMA is calculated twice as follows:

$D P M P=$

(PMP (LAST THREE MONTHS) + PMP (LAST THREE MONTS SAME AS THE MONTH FORECASTED)) / 2

Where

DPMP is double weighted moving average

PMP is the weighted moving average.

The SMAPE (symmetric average absolute percentage error) technique was used in the computer program as an assessment method of the forecast accuracy.

V. Collect the necessary data for the forecasts. A 3 years period of monthly historical sales data (2010-2012) was collected in order to make the sales forecast for the next twelve months. Excel software was used for the database and the preliminary analysis. Table 1 shows the historical sales data (2010-2012) for two of the fifty chemicals analyzed for company 1 . In the case of the company 2 , twenty-four products were analyzed.

Table 1. Three years (36 months) sales data for company 1, products 1 and 2

\begin{tabular}{|c|c|c|c|c|c|c|c|c|c|c|c|c|}
\hline & 1 & 2 & 3 & 4 & 5 & 6 & 7 & 8 & 9 & 10 & 11 & 12 \\
\hline I.1 & 85999 & 109148 & 161386 & 158400 & 145908 & 133005 & 252688 & 474882 & 374347 & 222749 & 309505 & 356227 \\
\hline II.1 & 375776 & 377311 & 514939 & 317637 & 236617 & 254699 & 405059 & 530239 & 258920 & 319859 & 360972 & 296114 \\
\hline \multirow[t]{2}{*}{ III.1 } & 310167 & 388850 & 359335 & 277029 & 293082 & 315182 & 362608 & 348899 & 246059 & 304941 & 296499 & 202061 \\
\hline & 1 & 2 & 3 & 4 & 5 & 6 & 7 & 8 & 9 & 10 & 11 & 12 \\
\hline 1.2 & 337032 & 299403 & 381836 & 387605 & 457823 & 525706 & 572672 & 449388 & 525816 & 374428 & 522622 & 310347 \\
\hline 11.2 & 503063 & 414015 & 450512 & 396477 & 412443 & 250992 & 250407 & 218011 & 303665 & 179865 & 11910 & 20337 \\
\hline 11.2 & 159718 & 267212 & 186576 & 148557 & 269495 & 180390 & 97987 & 309858 & 241382 & 210572 & 220952 & 138479 \\
\hline
\end{tabular}

VI. Perform the forecast: The algorithm of Figure 1 was used to develop the computer program that calculates the six quantitative techniques (Simple moving average, weighted moving average, projection of the trend, exponential smoothing, simple linear regression and the proposed technique called double-weighted moving average) and the SMAPE error. It also generates a graphic with the historical data and the forecasted values, and selects the least error technique. 


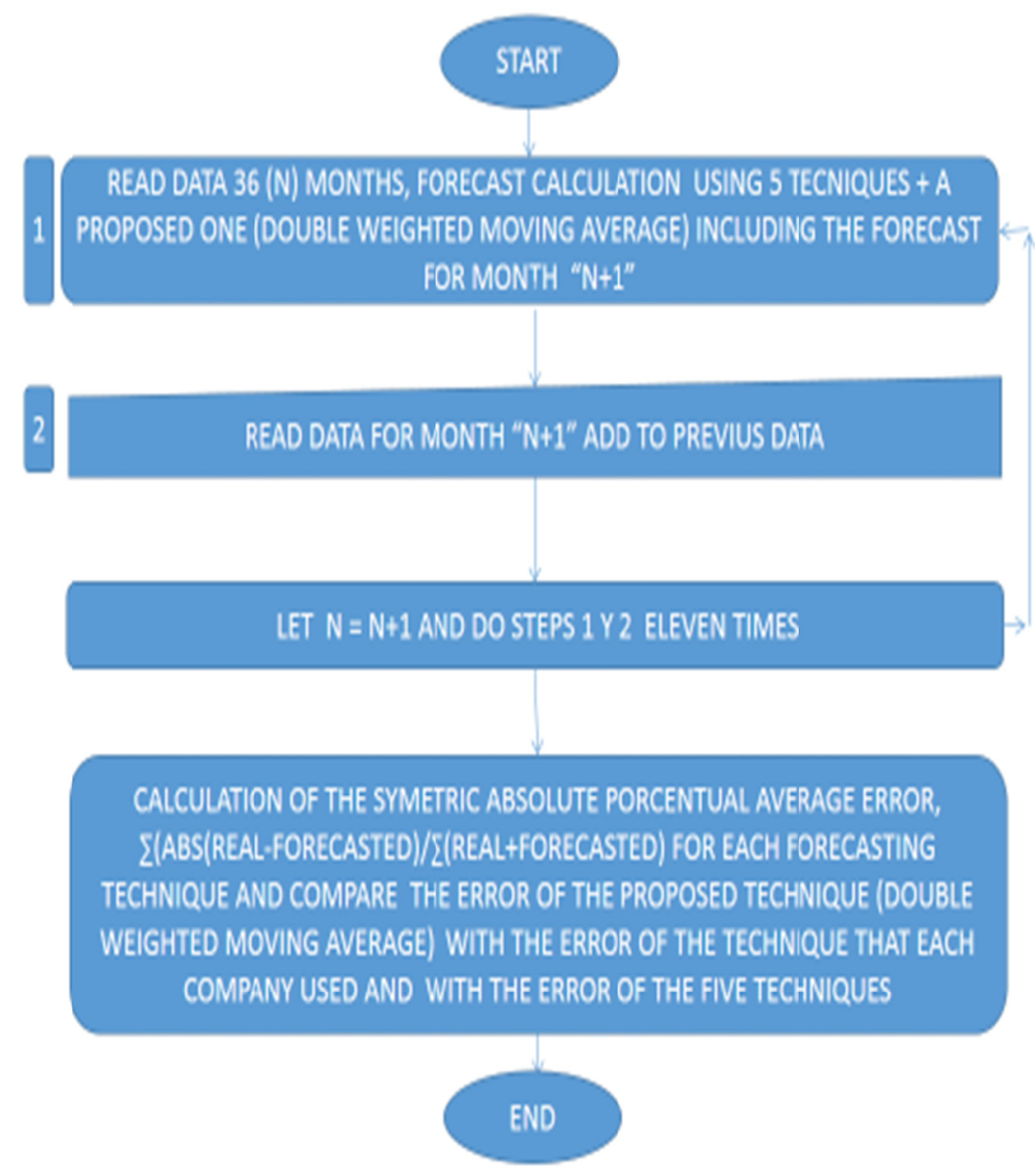

Figure 1. Algorithm used to develop the computer program that makes a twelve months sales forecast

The computer program was developed in Hyper Text Markup Language, HTML, the programming language PHP and the Apache server module of the XAMPP software; actually, program is in registration process in National Institute of Author Rights, under number SEP-INDAUTOR 03-2016-042510554500-01.

The program has features that allows us to read the data files, calculate six forecasting techniques (including the new proposed technique, DWMA), calculate the error of each prediction technique (SMAPE), plot the original data and the forecasting techniques results and select the most accurate technique. If the error value, of the minor error technique, is greater than 0.33 we recommend using this technique and a qualitative method. As a reference, in the case of company 1 , they use experts' opinion, and company 2 uses Delphi Method, as qualitative techniques.

A user's manual of the computer program is available from the authors. It contains the following chapters: System installation, system implementation considerations for archiving and database system menu.

VII. Validation of the results. The program results were compared with those obtained previously in Excel in order to verify the agreement of the two sets of values. To perform this step it was made a test with random numbers and later on with the data from two companies. Each month, the program is run with the newer data generated by de sales department, it determines the minor error technique with updated data and generates a new sales forecast.

\section{Results}

Some characteristic results, after running the sales forecast program, with the data of two Mexican chemicals suppliers are shown in Table No. 2 and Figures 2 to 5. 
Table 2. Techniques used and the percentage of products with lower error for the company 1 and 2

\begin{tabular}{lll}
\hline & Company 1 & Company 2 \\
\hline Double weighted moving average & 32.00 & 13.04 \\
\hline Weighted moving average & 26.00 & 0 \\
\hline Linear regression & 16.00 & 47.82 \\
\hline Exponential Smoothing & 12.00 & 4.34 \\
\hline Simple moving average & 10.00 & 26.08 \\
\hline Projecting the trend & 4.00 & 8.69 \\
\hline TOTAL & 100 & 99.97 \\
\hline
\end{tabular}

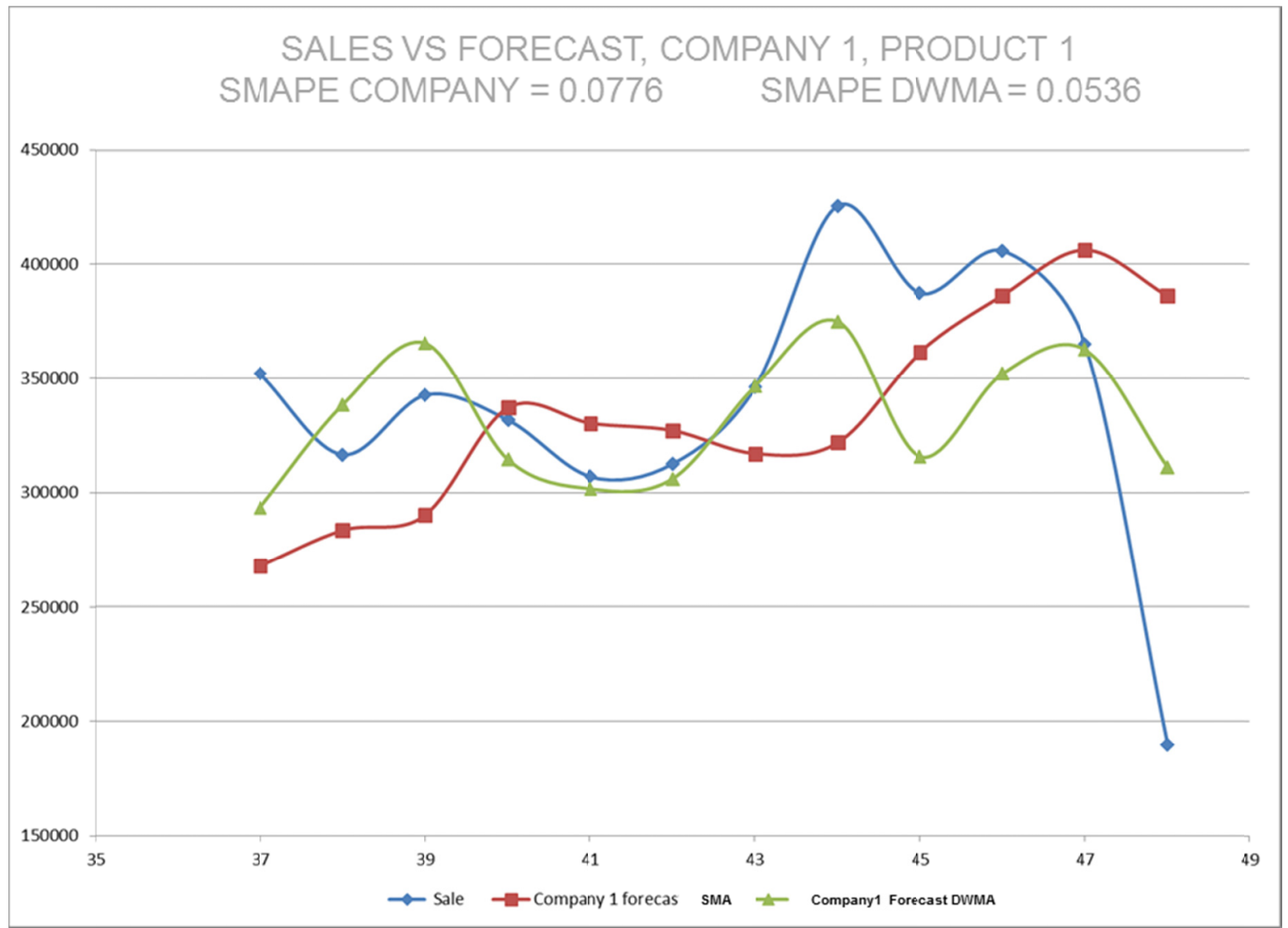

Figure 2. Comparison of actual sales (blue line) to the forecast of the company 1 technique simple moving average (red line) and the proposed technique double weighted moving average (green line) with a SMAPE $<0.33$

In the graphs one and two are represented: the actual sales values, the simple moving average forecast from company 1 , and those predicted by double weighted moving average technique. In both cases, the DWMA technique had the less error. These graphs are examples of the results obtained for $56 \%$ of company 1 forecasted products. 


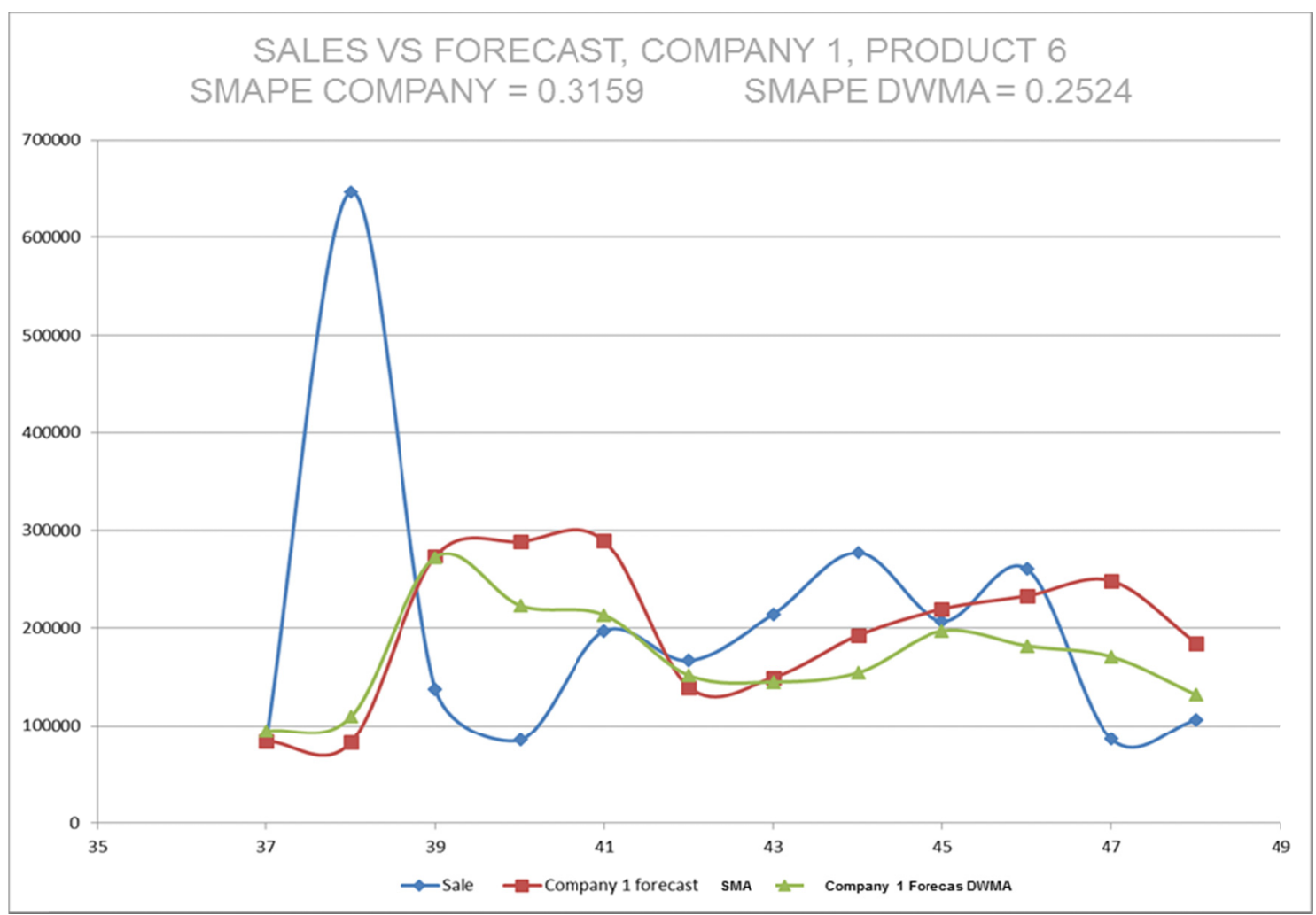

Figure 3. Comparison of actual sales (blue line) to the forecast of the company 1 simple technique moving average (red line) and the proposed technique double weighted moving average (green line) with a SMAPE $<0.33$

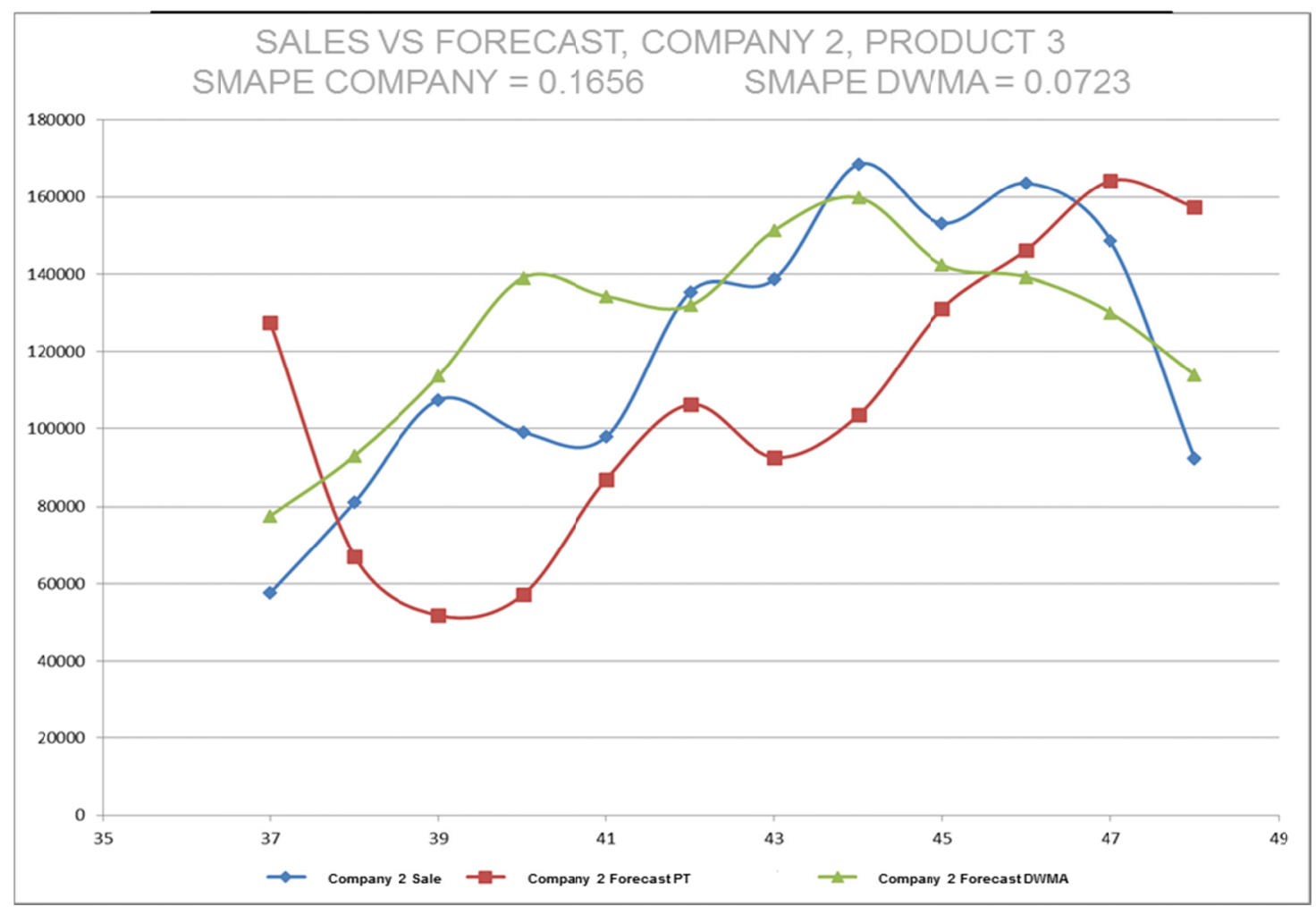

Figure 4. Comparison of actual sales (blue line) to the forecast of the company 2 technical projection of the trend (red line) and the proposed technique double weighted moving average (green line) with a SMAPE $<0.33$ 


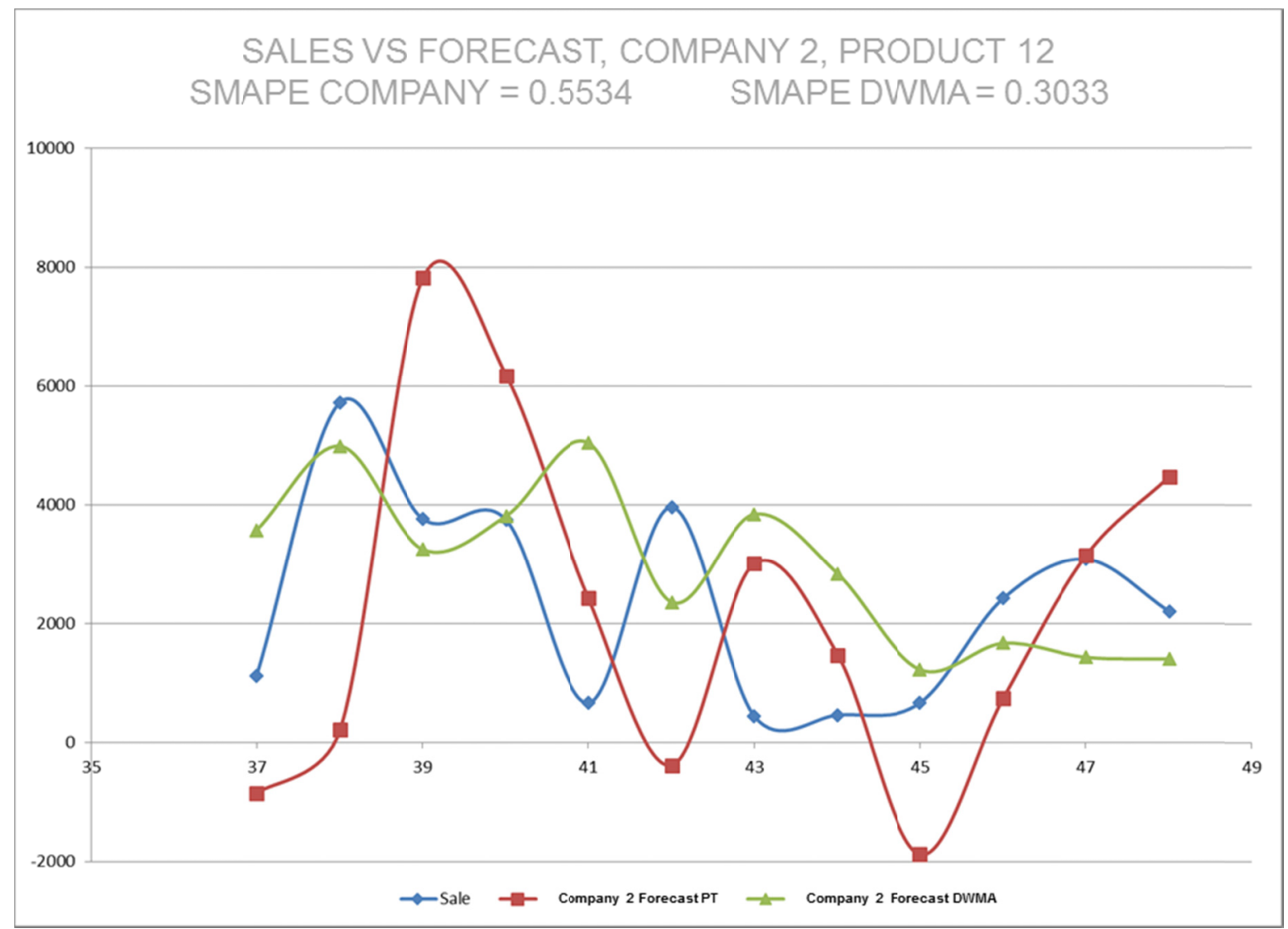

Figure 5. Comparison of actual sales (blue line) to the forecast of the company 2 technical projection of the trend (red line) and the proposed technique double weighted moving average (green line) with a SMAPE $<0.33$

In the graphs three to five are represented: the actual sales values, the trend projection forecasting technique used in company 2 , and those predicted by the double weighted moving average technique. In the three cases, the DWMA technique had the less error. These graphs are examples of the results obtained for $81.81 \%$ of company 2 forecasted products.

\section{Discussion}

The analysis of the company two sales data shows that in $45.8 \%$ of the products, the sales have zero or near zero values, in two or more monthly data per year. By using the SMAPE technique to measure the error of the sales forecast, based on these cero sales data, its value was always greater than 0.33 (SMAPE $>0.33$ ). This company uses the Delphi method, a qualitative forecasting technique, more successfully than any other quantitative technique, when forecasting with zero monthly sales values. With several data of cero monthly sales, it is recommended to change from quantitative techniques to a qualitative one, in order to produce a useful forecast.

\section{Conclusions}

From the analysis of two sets of sales data, we conclude that, it is possible to make short and medium term forecasts by using simple forecast models, as required for sales and operations planning. Assertion that matches with the results of Adya and Collopy (1998) and Chase, R. (2014).

For both companies most of the products forecasted by the Double Weighted Moving Average (DWMA) technique had lower SMAPE error than those forecasted by the preferred technique used by each company; in the case of company 1 , in $56 \%$ of products, in the case of company 2 , in $81.8 \%$ of products.

Analysis of data and errors of the company two, showed that when the error value is greater than 0.33 in real sales there are at least two or more zero values in monthly sales, i.e., no sales or marginal sales during those months, as compared with the rest of values of other monthly sales. In such cases it is recommended to use a qualitative technique to reinforce or correct the forecasted values. 


\section{References}

Adya, M., \& Collopy, F. (1998). How neural networks are effective at forecasting and prediction? A review and evaluation. Journal of $\quad$ Forecasting, $481-495$. http://dx.doi.org/10.1002/(SICI)1099-131X(1998090)17:5/6<481::AID-FOR709>3.0.CO;2-Q

Anderson, D., Sweeney, D., William, T., \& Camm, J. (2011). Quantitative methods for business. Mexico, D. F: Cengage Leaning.

Castillo, M. del R., Chain, M. M., Del Río, R., \& Cruz, M. J. (2015). Sales Forecasting System for Chemicals Supplying Enterprises. International Journal of Business Administration, 6, 39-47. http://dx.doi.org/10.5430/ijba.v6n3p39

Castillo, M. del R., Cruz, M. J., \& Abascal, L. O. (2016). Sistema para la predicción de ventas de empresas proveedoras de productos químicos. Registro público 03-2016-04251055450001. Instituto Nacional del Derecho de Autor. México.

Chase, B.R., \& Jacobs, F.R. (2014). Operations Management. Production and supply chain. Mexico City: McGraw Hill Education.

Chase, R., Aquilano, N., \& Jacobs, R. (2004). Production and Operations Management manufacturing and services. México, DF: McGraw-Hill.

Chopra, S., \& Meindl, P. (2010). Supply chain management. Mexico, DF: Prentice Hall.

Chu, C.H., \& Zhang, G. (2003). A comparative study of linear and nonlinear models for forecasting aggregate retail $\begin{array}{llllll}\text { sales. International Journal of Production Economics, } & 86, & \text { 217-231. }\end{array}$ http://dx.doi.org/10.1016/S0925-5273(03)00068-9

Collier, D., \& Evans, J. (2009). Operations and value chain management services. México, D. F: Cengage Learning. Corres, G. et al. (2009). Time Series Analysis Forecasts definition. Industrial Engineering Magazine, 8(1), 21-33.

Durbin, J., \& Koopman, S. (2001). Times Series Analysis by space methods. London: Oxford University Press.

Everett \& Ronald. (2000). Production and Operations Administration. México, DF: Prentice Hall Hispano American. Grawford, M., \& Di Benedetto, A. (2011). New Products Management. New York: McGraw-Hill.

Hanmias, S. (2007). Production and Operations Analysis. México, DF: McGraw Hill.

Heizer, J., \& Render, B. (2009). Principles of Operations Management. México City: Pearson Prentice Hall.

Henke, J., \& Reitch, A. (2001). Business forecasting. New Jersey: Prentice-Hall.

Hill, C., \& Jones G. (2009). Strategic Management. México, DF: McGraw Hill.

Monks, J. (2004). Operations Management. México, DF: McGraw-Hill.

Pérez, R. A, Mosquera, S. A., \& Bravo, J.J. (2012). Application of Forecasting Models in products of massive consumption. Biotechnology in the Agricultural and Agribusiness Sector, 10(2), 117-125.

Taha, H. (2004). Operations Research. México City: Pearson Education.

Thompson, E. (2014). Striking a balance Between Sales and Operations in the Forecasting Process, Journal of Business Forecasting, Winter, 2013-2014.

Vidal, C., Londoño, J., \& Contreras, F. (2004, September). Application of inventory to supply chain models in consumer products with a Storage and $\mathrm{N}$ outlets. Retrieved April 3, 2012, from http://web.ebscohost.com/ehost/pdfviewer/pdfviewer?vid=3\&hid=19\&sid=dd78005c-4cac-4fec-935b-a02f8fff8 $32 \mathrm{a} \% 40$ sessionmgr 10

Winston, W. (2005). Operations Research Applications and Algorithms. México, DF: Thomson. 